\title{
BMJ Open Glycosylated haemoglobin for screening and diagnosis of gestational diabetes mellitus
}

\author{
Alhossain Khalafallah, ${ }^{1,2,3}$ Eileen Phuah, ${ }^{4}$ Abdul Majeed Al-Barazan, ${ }^{2}$ \\ Irena Nikakis, ${ }^{4}$ Andrea Radford, ${ }^{5}$ Wade Clarkson, ${ }^{5}$ Clinton Trevett, ${ }^{5}$ Terry Brain, ${ }^{5}$ \\ Val Gebski, ${ }^{6}$ Anne Corbould ${ }^{1,2}$
}

To cite: Khalafallah $A$, Phuah E, Al-Barazan AM, et al. Glycosylated haemoglobin for screening and diagnosis of gestational diabetes mellitus. BMJ Open 2016;6:e011059.

doi:10.1136/bmjopen-2016011059

- Prepublication history for this paper is available online. To view these files please visit the journal online (http://dx.doi.org/10.1136/ bmjopen-2016-011059).

Received 9 January 2016 Revised 9 March 2016 Accepted 14 March 2016

CrossMark

For numbered affiliations see end of article.

Correspondence to Professor Alhossain Khalafallah; khalafallah@ dhhs.tas.gov.au

\section{ABSTRACT}

Objectives: The oral glucose tolerance test (OGTT) is a cumbersome test that is time consuming, labour intensive and often poorly tolerated by pregnant women. To date, glycosylated haemoglobin (HbA1c) is the most accepted measure of chronic glycaemia outside of pregnancy. HbA1c is an uncomplicated test, less time consuming, does not require any specific patient preparation and is considered straightforward compared with the OGTT. Therefore, we prospectively tested the utility of the HbA1c when used as a screening tool in pregnancy for gestational diabetes mellitus (GDM).

Settings: Primary health care. Single tertiary referral centre, Tasmania, Australia.

Participants: A direct comparison between HbA1c levels and the OGTT results in pregnant women, tested concurrently at the 24-28 gestational week, was undertaken. A full profile of 480 pregnant women during the period from September 2012 to July 2014 was completed. Median and mean age of participants was 29 years (range 18-47 years).

Interventions: A simultaneous prospective assessment of $\mathrm{HbA} 1 \mathrm{c}$ versus standard OGTT in a cohort of consecutive pregnant women presenting to our institute was performed.

Results: The number of women who had GDM according to OGTT criteria was 57 , representing $11.9 \%$ of the evaluated 480 pregnant women. Using a cut-off value for $\mathrm{HbA} 1 \mathrm{c}$ at $5.1 \%(32 \mathrm{mmol} / \mathrm{mol})$ for detecting GDM showed sensitivity of $61 \%$ and specificity of $68 \%$ with negative predictive value (NPV) of $93 \%$, versus sensitivity of $27 \%$ and specificity of $95 \%$ with NPV of $91 \%$ when using $\mathrm{HbA} 1 \mathrm{c}$ cut-off value of $5.4 \%(36 \mathrm{mmol} / \mathrm{mol})$.

Conclusions: Our results suggest that pregnant women with an $\mathrm{HbA} 1 \mathrm{c}$ of $\geq 5.4 \%(36 \mathrm{mmol} / \mathrm{mol})$ should proceed with an OGTT. This may result in a significant reduction in the burden of testing on both patients and testing facility staff and resources. Further investigations are required to integrate and optimise the HbA1c as a single, non-fasting, screening tool for GDM.

Trial registration number: ACTRN12611000739910.

\section{Strengths and limitations of this study}

- Oral glucose tolerance test is a standard screening test for gestational diabetes mellitus (GDM); however, it requires fasting overnight and three separate blood tests over $2 \mathrm{~h}$, is often poorly tolerated by pregnant women and is labour intensive, adding an additional burden to an overstretched health system.

- Glycosylated haemoglobin ( $\mathrm{HbA1c}$ ) is a simple, single, non-fasting test that may give insight to gestational diabetes.

- Our study of 480 pregnant women suggests that HbA1c could be a useful screening tool for GDM.

- The diagnosis of GDM would be missed in few patients by using $\mathrm{HbA1c}$ as a screening tool.

- The major effect on $\mathrm{HbA1C}$ is usually seen in the last 4-8 weeks of red cell age. Thus, it should be interpreted with caution if detecting a new diagnosis of GDM.

\section{INTRODUCTION}

Pregnancies affected by gestational diabetes mellitus (GDM) are at risk of developing a number of serious obstetric complications such as fetal growth abnormalities, shoulder dystocia, birth injury, prematurity and increased Caesarean section rate, as well as having long-term implications for the wellbeing of mother and infant. ${ }^{1}$ The risk of adverse perinatal and maternal outcomes is directly proportional to the degree of hyperglycaemia, with a linear relationship between maternal glucose and various neonatal outcomes. $^{1-2}$

The current screening process using the revised Australasian Diabetes in Pregnancy Society (ADIPS) guidelines published in 2013 based on the International Association of Diabetes and Pregnancy Study Groups (IADPSG) criteria has resulted in an increase in the detected incidence of GDM in the 
Australian population from $6-8 \%$ to $13 \% .^{2}$ The guidelines recommend a $75 \mathrm{~g}$ oral glucose tolerance test (OGTT) at 24-28 weeks gestation for all pregnant women.

However, the OGTT is a cumbersome test that is time consuming, labour intensive and often poorly tolerated by pregnant women. The patient must be fasted, sit for over $2 \mathrm{~h}$ and have at least three venipunctures. The gravida is prone to nausea and vomiting from delayed gastric emptying. This, coupled with gestational oedema compromising venous access, can lead to an invalid test result. Furthermore, the recommendation for universal screening has significantly increased the burden of testing.

The instability of blood glucose ex vivo leads to significant interlaboratory variation of results. It is thought to vary by up to $14 \%$ in a third of cases. ${ }^{3}$

While guidelines are in place, the glucose threshold values for diagnosis and methods of testing for GDM vary greatly from one institution to another. Moreover, as it is a specialised test, many collection centres do not provide this service, particularly in rural and remote locations, potentially disadvantaging an already vulnerable cohort of women. ${ }^{4}$

The need for a simpler, more universally acceptable and accessible test is becoming increasingly apparent. Glycosylated haemoglobin (HbAlc) is currently the most accepted measure of chronic glycaemia outside of pregnancy.

The National Health and Medical Research Council (NHMRC) guidelines 2009 recommend HbAlc to be the basis for diagnosis of type 2 diabetes mellitus, with a value of $48 \mathrm{mmol} / \mathrm{mol}$ or $6.5 \%$ or greater being confirmatory. ${ }^{5}$

HbA1c is the product of an irreversible non-enzymatic binding of glucose to plasma proteins, specifically haemoglobin $(\mathrm{Hb})$. The mean plasma glucose over the erythrocyte life span is correlated with a degree of glycosylation. It is a single, non-fasting blood test and reflects glucose levels over the previous 4-8 weeks. As compared with glucose testing, it has been shown to have greater reliability with $<6 \%$ interlaboratory variation. ${ }^{3}$ Thus, HbA1c test has improved analytical stability with greater standardisation between assays and less preanalytical variation. Further comparisons with fasting blood glucose and $2 \mathrm{~h}$ postprandial glucose have shown HbA1c to have less intraindividual variation ${ }^{6}$ as it does not appear to be affected by diurnal variation, meals, fasting, acute stress or by the large number of common drugs known to influence glucose metabolism. ${ }^{7}$ The test is validated for a red cell survival time of approximately 3 months. Therefore, results need to be interpreted carefully in the clinical situation whereby erythrocyte half-life is significantly shortened by, for example, haemoglobinopathies, haemolysis, transfusion, anaemia and chronic renal failure.

Dilutional anaemia of pregnancy and increased erythrocyte turnover have, to date, hampered its acceptance as a tool for screening, if not diagnosis, of GDM. ${ }^{8}$
The accuracy of HbA1c as a screening test in pregnancy has been extensively studied over the past three decades and results have been inconsistent. ${ }^{9-13}$

Many of these studies were conducted prior to the Hyperglycaemia and Adverse Pregnancy Outcome (HAPO 2008) findings, ${ }^{14}$ on which the current IADPSG $2010^{15}$ and ADIPS $^{2}$ screening strategies are based. Consequently, there is significant heterogeneity in both methods used for screening for GDM and diagnostic glucose thresholds when compared with HbAlc. In addition, and importantly, many studies have used the same reference range for HbAlc in both pregnant and nonpregnant patients. Nonetheless, the results of these studies have been inconclusive. The overlap of HbAlc values between normal and GDM-affected pregnancies has always been too great for HbA1c to have sufficient sensitivity and specificity to meet the screening requirements of a test.

Using current screening guidelines, Nielsen et $a l^{16}$ have shown the normal upper range of HbAlc in early pregnancy to be significantly lower than levels found outside of pregnancy $(5.7 \% / 39 \mathrm{mmol} / \mathrm{mol})$ and did not significantly differ from late pregnancy $(5.6 \% / 38 \mathrm{mmol} /$ mol). This study looked at non-GDM women at 14 and 33 weeks gestation as determined by negative OGTT values. $\mathrm{Hb}$ levels, however, were not accounted for and anaemia could have inadvertently lowered results.

O'Connor et $a l^{17}$ did find trimester-specific reference intervals for HbAlc in a study of 246 non-diabetic pregnant women with normal $\mathrm{Hb}$ levels: the first trimester range was $4.8-5.5 \%(29-37 \mathrm{mmol} / \mathrm{mol})$, second trimester $4.4-5.4 \%(25-36 \mathrm{mmol} / \mathrm{mol})$ and third trimester 4.4-5.4\% (25-36 mmol/mol).

A meta-analysis of 43 studies, involving over 2812 patients with GDM in China compared with 5918 controls concluded that, based on the summary receiver operating characteristic (ROC) curve analysis, HbA1c is a useful diagnostic tool for confirming GDM. ${ }^{18}$ Studies from 2001 to 2012 were included in this meta-analysis with varying diagnostic criteria for GDM and cut-off values for HbAlc, such that the authors recommended HbAlc to be tested in parallel with conventional tests. ${ }^{18}$

Our current study is focusing on parallel prospective comparison between the HbAlc and standard OGTT when used as a screening tool in pregnancy for GDM.

\section{Objectives of the study}

The aim of the study was to provide an objective assessment of the utility of HbAlc when used as a screening tool in pregnancy. A direct comparison of HbAlc levels with results of the OGTT in women, tested concurrently at the 24-28 gestational week, was undertaken.

\section{PATIENTS AND METHODS}

\section{Participants}

We recruited 480 pregnant women during the period from September 2012 to July 2014. For these patients, 
we performed a simultaneous prospective assessment of HbAlc versus standard OGTT in a cohort of consecutive pregnant women presenting to the Launceston General Hospital (LGH; a tertiary referral teaching hospital in Tasmania, Australia). Pregnant women were approached when attending their routine third trimester OGTT test at our institution. Written informed consent was obtained from all participants. For these patients, simultaneous full blood count (FBC) and iron studies were performed as per our routine antenatal assessment. Median and mean age of participants was identical 29 years (range 18-47).

The trial was registered in the Australian New Zealand Clinical Trials Registry (http://www.anzctr.org.au/ ACTRN12611000739910.aspx) and the WHO Clinical Trials Registry (http://www.who.int/trialsearch/Trial2. aspx?trialid=ACTRN12611000739910).

\section{Inclusion criteria}

All sequential pregnant women who were $\geq 18$ years old and presented for OGTT test at 24-28 weeks gestation in our tertiary referral hospital were offered the trial. The OGTT was performed according to our policy at the LGH at the time of study.

\section{Exclusion criteria}

Twin pregnancies were excluded as well as women with an early diagnosis of GDM, that is, prior to 24 weeks gestation as this may create unknown bias to the results of the trial.

Parameters such as gravity, parity, ethnicity, personal and family history of diabetes, type of delivery, complications of pregnancy, body mass index and perinatal data, as well as data regarding the infants' APGAR scores, weight and sex were collected prospectively from women enrolled in the trial after informed consent.

OGTT was performed according to our standard protocol. The patient was required to have been in good health and to be consuming a normal diet, particularly with regard to carbohydrate intake $(>150 \mathrm{~g} /$ day). The test was performed after an overnight fast of $10 \mathrm{~h}$. The test was started before 10:00 and the patient remained resting quietly for the duration of the OGTT. Blood samples were collected into Becton Dickinson $2 \mathrm{~mL}$ Fluoride Oxalate Vacutainer tubes. A sample was collected at baseline and then the patient consumed the $75 \mathrm{~g}$ glucose load. We used a commercially available product containing $75 \mathrm{~g}$ of dextrose in $300 \mathrm{~mL}$ carbonated liquid (SteriHealth Gluco Scan $75 \mathrm{~g}$ ). The patient was required to consume the whole volume within $5 \mathrm{~min}$ of starting the drink. Further blood samples were collected at 1 and $2 \mathrm{~h}$ post-start of the dextrose drink. Glucose was measured within $3 \mathrm{~h}$ of collection of the sample using the Abbott glucose hexokinase method on an Architect C8000 analyser (Abbott Australasia Pty Ltd).

HbA1c samples were collected into Becton Dickinson 4 mL K2EDTA Vacutainer tubes.
HbA1c was measured by immunoassay using the DCA 2000 (Siemens Ltd, Marburg, Germany). The DCA 2000 analyser measures HbA1c standardised to the National Glycohemoglobin Standardization Program (NGSP), which is in turn aligned to the Diabetes Control and Complications Trial (DCCT) results with international standardisation as set by the International Federation of Clinical Chemistry (IFCC; http://www.ngsp.org/ certified.asp).

GDM was defined as present if fasting blood glucose was $\geq 5.1 \mathrm{mmol} / \mathrm{L}$ or glucose tolerance test (GTT) $1 \mathrm{~h}$ $\geq 10.0 \mathrm{mmol} / \mathrm{L}$ OR GTT $2 \mathrm{~h} \geq 8.5 \mathrm{mmol} / \mathrm{L}$. GDM was defined as not present if fasting blood glucose was $<5.1 \mathrm{mmol} / \mathrm{L}$ and GTT $1 \mathrm{~h}<10 \mathrm{mmol} / \mathrm{L}$ and GTT $2 \mathrm{~h}$ $<8.5 \mathrm{mmol} / \mathrm{L}$. The diagnostic criteria are defined by the 2013 ADIPS consensus guidelines for the testing and diagnosis of GDM in Australia. ${ }^{5} 19$

\section{STATISTICAL ANALYSIS}

Patient characteristics were expressed as percentages for categorical variables, and as mean and SD, or median with IQR for continuous variables.

Groups were compared using t test, and multiplecategory variables were analysed using analysis of variance.

Bland-Altman plot was used to assess the agreement between HbA1c levels and the values of the GTT. ROC curve was performed to assess the discriminative capacity of HbAlc for detection of GDM. Sensitivity, specificity, predictive values, false-positive and false-negative rates were calculated. All analyses were performed with SAS (V.9.3).

\section{RESULTS}

We recruited 480 women with a median of 26 and mean of 25.7 weeks gestation. Approximately $12 \%$ of our cohort were diagnosed with GDM according to the ADIPS criteria, and this is consistent with the expected incidence of GDM in Australia.

The median gestational age at enrolment was 26 weeks with a mean of 25.7 weeks (SD 3.3) with a mean fasting glucose level of $4.37 \mathrm{mmol} / \mathrm{L}$ (SD 0.46), $6.85 \mathrm{mmol} / \mathrm{L}$ (SD 1.7) at $1 \mathrm{~h}$ and $5.84 \mathrm{mmol} / \mathrm{L}(\mathrm{SD} 1.45)$ at $2 \mathrm{~h}$. The mean HbA1c was $4.8 \%(29 \mathrm{mmol} / \mathrm{mol}$; SD 0.36). FBC and iron studies were assessed in the same participants, showing median $\mathrm{Hb}$ of $119 \mathrm{~g} / \mathrm{L}$ (range 92-145) and median ferritin of $12 \mu \mathrm{g} / \mathrm{L}$ (range 1-204).

Spearman correlation between OGTT and HbA1c showed significant association of 1 and $2 \mathrm{~h}$ OGTT with HbAlc ( $\mathrm{p} \leq 0.0001$; table 1$)$. However, no such correlation existed for $\mathrm{Hb}$ and OGTT $(\mathrm{p}=0.38$ and 0.25 , respectively). Further analyses demonstrated that ferritin and Hb levels correlated with HbA1c $(\mathrm{p}=0.02, \mathrm{p} \leq 0.0001$, respectively; table 1). Bland-Altman correlations between OGTT and HbAlc are shown in figures 1 and 2.

The number of women in our cohort who had GDM according to the OGTT criteria was 57, representing 
Table 1 Spearman correlations between OGTT and HbA1c

\begin{tabular}{|c|c|c|c|c|c|c|}
\hline \multicolumn{7}{|c|}{$\begin{array}{l}\text { Spearman correlation coefficients } \\
\text { Probability >lrl under H0: } r=0 \\
\text { Number of observations }\end{array}$} \\
\hline & $\begin{array}{l}\text { Fasting blood } \\
\text { glucose }\end{array}$ & $\begin{array}{l}\text { OGTT (mmol/L) } \\
1 \mathrm{~h}\end{array}$ & $\begin{array}{l}\text { OGTT (mmol/L) } \\
2 \mathrm{~h}\end{array}$ & $\begin{array}{l}\text { HbA1c } \\
(\%)\end{array}$ & Ferritin & $\mathrm{Hb}$ \\
\hline $\begin{array}{l}\text { Fasting blood } \\
\text { glucose }\end{array}$ & 1.00000 & & & & & \\
\hline OGTT $(\mathrm{mmol} / \mathrm{L}) / 1 \mathrm{~h}$ & $\begin{array}{l}0.36109 \\
<0.0001 \\
475\end{array}$ & 1.00000 & & & & \\
\hline OGTT (mmol/L) $2 \mathrm{~h}$ & $\begin{array}{l}0.31745 \\
<0.0001 \\
480\end{array}$ & $\begin{array}{l}0.61037 \\
<0.0001 \\
475\end{array}$ & 1.00000 & & & \\
\hline HbA1c (\%) & $\begin{array}{l}0.34298 \\
<0.0001 \\
438\end{array}$ & $\begin{array}{l}0.21911 \\
<0.0001 \\
434\end{array}$ & $\begin{array}{l}0.22906 \\
<0.0001 \\
438\end{array}$ & 1.00000 & & \\
\hline Ferritin & $\begin{array}{l}0.03316 \\
0.4757\end{array}$ & $\begin{array}{l}0.11589 \\
0.0129\end{array}$ & $\begin{array}{l}0.00636 \\
0.8912\end{array}$ & $\begin{array}{l}-0.10974 \\
0.0233\end{array}$ & 1.00000 & \\
\hline $\mathrm{Hb}$ & $\begin{array}{l}465 \\
-0.03201 \\
0.4860\end{array}$ & $\begin{array}{l}460 \\
0.03996 \\
0.3869\end{array}$ & $\begin{array}{l}465 \\
-0.05220 \\
0.2557\end{array}$ & $\begin{array}{l}427 \\
-0.26569 \\
<0.0001\end{array}$ & $\begin{array}{l}0.23075 \\
<0.0001\end{array}$ & 1.00000 \\
\hline & 476 & 471 & 476 & 436 & 463 & \\
\hline
\end{tabular}

$\mathrm{Hb}$, haemoglobin; HbA1c, glycosylated haemoglobin; OGTT, oral glucose tolerance test.

$11.9 \%$ of the 480 studied pregnant women. Overall, in the same trial period at our laboratory, there were 97 out of 1795 pregnant women $(5.4 \%)$ tested for OGTT who had a fasting blood glucose level $>5.1 \mathrm{mmol} / \mathrm{L}$, while at $2 \mathrm{~h}$, the glucose level was $>8.5 \mathrm{mmol} / \mathrm{L}$ in 96 out of 1775 patients $(5 \%)$.

It is worth noting that most of the patients studied (88\%) were iron deficient with ferritin level $<30 \mu \mathrm{g} / \mathrm{L}$, while $57 \%$ had ferritin $<15 \mu \mathrm{g} / \mathrm{L}$ similar to the results of previous trials. ${ }^{20-22}$ The HbAlc distribution by GDM status is shown in figure 3 .

Using an arbitrary cut-off value for HbAlc at 5.1\% $(32 \mathrm{mmol} / \mathrm{mol})$ to detect GDM showed sensitivity of $61 \%$ and specificity of $68 \%$ with negative predictive value (NPV) of $93 \%$ versus sensitivity of $27 \%$ and

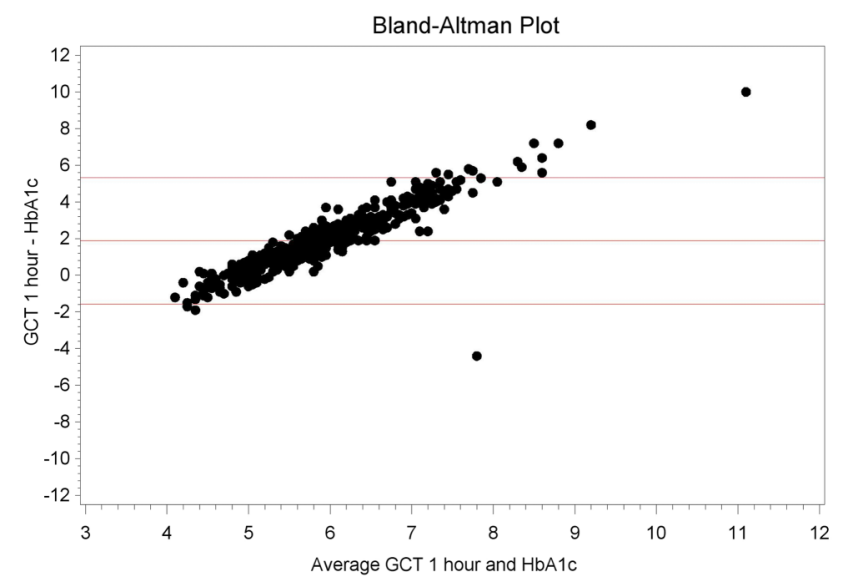

Figure 1 Bland-Altman plot, oral glucose challenge test (GCT) $1 \mathrm{~h}$ versus glycosylated haemoglobin ( $\mathrm{HbA} 1 \mathrm{c})$. specificity of $95 \%$ with NPV of $91 \%$ when using a HbAlc cut-off value of $5.4 \%$ (36 mmol/mol; table 2$)$.

Regarding ethnicity, 93\% of the population studied were Caucasian, with 4\% Asian and 3\% Aboriginal. There was no significant correlation between GDM or HbAlc and ethnicity. Nevertheless, this study is not statistically powered to detect such differences as other trials demonstrated. ${ }^{23}$

The sex of the baby, complications of pregnancy or type of delivery did not show an association to HbAlc levels. However, GDM itself was associated with more complications during pregnancy $(\mathrm{p}<0.0001)$ compared with non-GDM pregnant women but did not influence intrapartum or postpartum or natal complications (table 3).

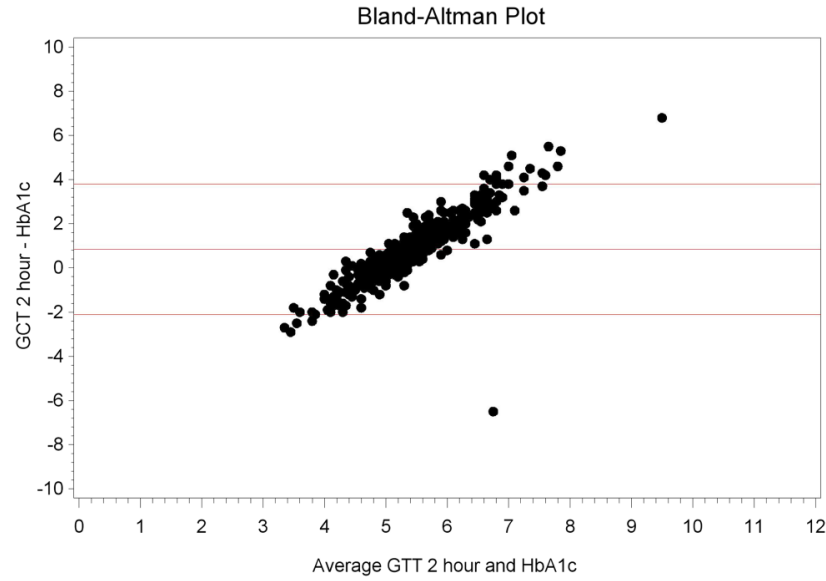

Figure 2 Bland-Altman plot, oral glucose tolerance test (OGTT)/glucose challenge test (GCT) $2 \mathrm{~h}$ versus glycosylated haemoglobin (HbA1c). 


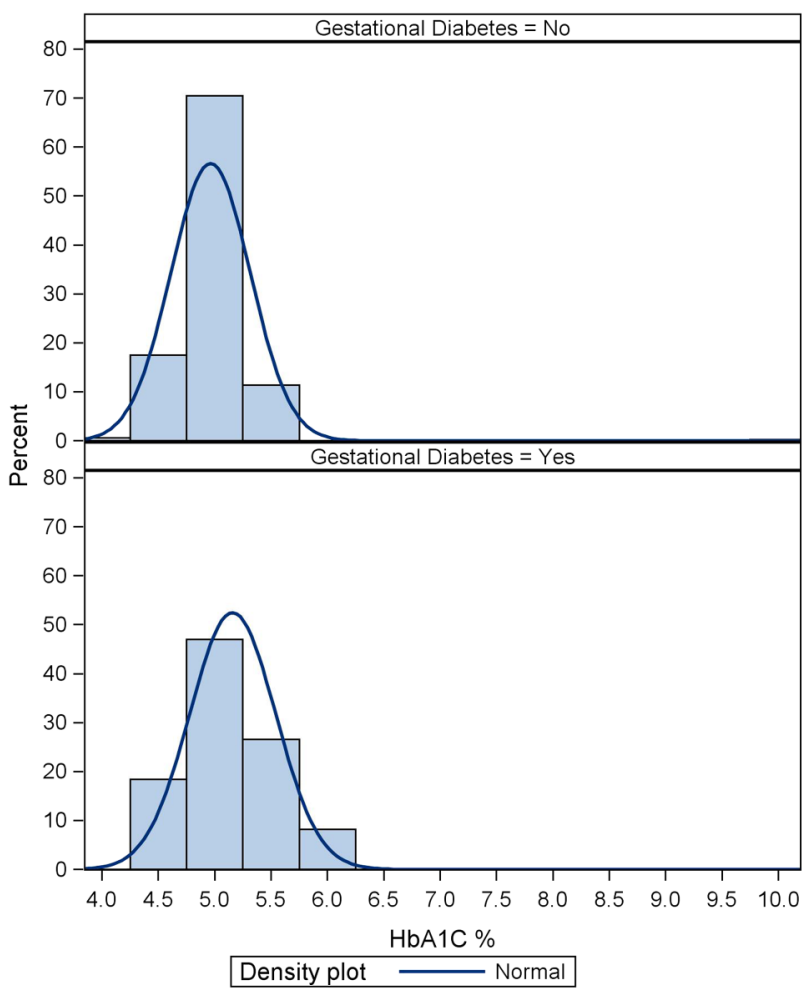

Figure 3 Glycosylated haemoglobin (HbA1c) distribution by gestational diabetes mellitus (GDM) status.

\section{Proposed cost saving}

The use of HbAlc in the context of gestational diabetes screening provides an economy at the point of specimen collection. The resource requirement for the specimen collection facility may be significantly reduced, for example, bleeding a patient once for an HbAlc as opposed to three times for a GTT (baseline, 1 and $2 \mathrm{~h}$ ).

\begin{tabular}{|c|c|c|c|c|}
\hline HbA1c (\%) & Sensitivity & Specificity & PPV & NPV \\
\hline 10 & 0 & 0.997 & 0 & 0.888 \\
\hline 6.1 & 0.02 & 0.997 & 0.5 & 0.89 \\
\hline 6 & 0.041 & 0.997 & 0.667 & 0.892 \\
\hline 5.9 & 0.061 & 0.997 & 0.75 & 0.894 \\
\hline 5.8 & 0.082 & 0.997 & 0.8 & 0.896 \\
\hline 5.7 & 0.102 & 0.995 & 0.714 & 0.898 \\
\hline 5.6 & 0.122 & 0.99 & 0.6 & 0.9 \\
\hline 5.5 & 0.224 & 0.982 & 0.611 & 0.91 \\
\hline 5.4 & 0.265 & 0.954 & 0.419 & 0.912 \\
\hline 5.3 & 0.347 & 0.884 & 0.274 & 0.915 \\
\hline 5.2 & 0.551 & 0.797 & 0.255 & 0.934 \\
\hline 5.1 & 0.612 & 0.676 & 0.192 & 0.933 \\
\hline 5 & 0.694 & 0.519 & 0.154 & 0.931 \\
\hline 4.9 & 0.735 & 0.314 & 0.119 & 0.904 \\
\hline 4.8 & 0.816 & 0.18 & 0.111 & 0.886 \\
\hline 4.7 & 0.959 & 0.1 & 0.118 & 0.951 \\
\hline 4.6 & 0.959 & 0.046 & 0.112 & 0.9 \\
\hline
\end{tabular}

HbA1c, glycosylated haemoglobin; NPV, negative predictive value; PPV, positive predictive value.
Table 3 Does gestational diabetes mellitus (GDM) status influence complications during pregnancy, intrapartum and postpartum?

\begin{tabular}{|c|c|c|c|}
\hline & \multicolumn{2}{|c|}{ GDM status (N, \%) } & \multirow[b]{2}{*}{ p Value } \\
\hline & $\begin{array}{l}\mathbf{0}=\text { No } \\
\text { gestational } \\
\text { diabetes }\end{array}$ & $\begin{array}{l}\text { 1=Gestational } \\
\text { diabetes }\end{array}$ & \\
\hline \multicolumn{4}{|c|}{ Complications during pregnancy } \\
\hline $1=$ No & $305(97)$ & $8(3)$ & $<0.0001$ \\
\hline $2=$ Yes & $95(68)$ & $45(32)$ & - \\
\hline $\begin{array}{l}3=\text { Insufficient } \\
\text { information }\end{array}$ & $21(91)$ & $2(9)$ & - \\
\hline \multicolumn{4}{|c|}{ Intrapartum complications } \\
\hline $1=$ No & $378(88)$ & $52(12)$ & 0.8203 \\
\hline $2=$ Yes & $20(87)$ & $3(13)$ & - \\
\hline $\begin{array}{l}3=\text { Insufficient } \\
\text { information }\end{array}$ & $23(92)$ & $2(8)$ & - \\
\hline \multicolumn{4}{|c|}{ Postpartum complications } \\
\hline $1=$ No & $362(88)$ & $50(12)$ & 0.9047 \\
\hline $2=$ Yes & $36(88)$ & 5 (12) & - \\
\hline $\begin{array}{l}3=\text { Insufficient } \\
\text { information }\end{array}$ & $23(92)$ & $2(8)$ & - \\
\hline
\end{tabular}

Consumables and equipment, salaries and accommodation are also reduced which may, over time, support an economic argument.

\section{Cost of OGTT and HbA1c}

Although a cost analysis was not the primary objective of the study, it is worthwhile attempting to calculate approximate costs of consumables/equipment/accommodation per bleed.

In our laboratory, the cost of reagents and consumables to perform an HbA1c is approximately US $\$ 9.00$. This is compared with the cost of performing the three glucose tests as part of an OGTT which is in the order of $\$ 0.50$.

This increased cost of laboratory consumables is more than offset by the reduction in labour and infrastructure costs of collecting a single sample for HbAlc compared with performing the OGTT.

At the LGH public laboratory, the laboratory consumable cost per bleed is approximately US $\$ 2$, and the salary of the nurse performing the venipuncture is approximately $\$ 10$ per bleed. The cost of testing an additional blood sample is approximately $\$ 9$ per given episode. It therefore costs $\$ 12.00$ to perform the single blood collection for an HbA1c and \$34 for the OGTT. In addition, the $75 \mathrm{~g}$ glucose load for the OGTT costs $\$ 2$. The overall cost of performing the two procedures is approximately $\$ 21$ for an HbAlc and $\$ 36.50$ for an OGTT, a saving of $\$ 15.50$ per episode for HbAlc compared with OGTT.

Furthermore, in health systems that often have resourcing issues such as staff and accommodation, it is far more efficient to have a patient bled once rather than 
three times and accommodate them (and their party) in the waiting room for more than $2 \mathrm{~h}$.

Furthermore, there is an economy for the patients themselves in terms of time off work, parking and issues such as child care when applicable.

\section{DISCUSSION}

Since the time of the original publications investigating the value of HbA1c for GDM diagnosis, laboratory testing of HbAlc has become increasingly standardised and evolved to be a simpler, more accurate and automated test. It has developed from simple ELISA to turbidometric inhibition immunoassay, an assay method largely unaffected by either haemoglobinopathies or uraemia, through to precision liquid chromatography. Previously, HbAlc results could not be compared between one laboratory and another let alone one country to another. ${ }^{24}$ However, since international standardisation of the assay, this is no longer the case.

Rajput and colleagues 2012 studied 607 women between 24 and 28 weeks' gestation, similar to our study. They were evaluated for GDM using OGTT based on American Diabetes Association (ADA) criteria $(2 \mathrm{~h} 75 \mathrm{~g}$ OGTT or 'one-step strategy') and concurrently tested for HbAlc. ${ }^{25}$ A cut-off value of $\geq 5.4 \%(36 \mathrm{mmol} / \mathrm{mol})$ had a sensitivity of $85.7 \%$ and specificity of $61.1 \%$. Only $2.8 \%$ would have been diagnosed incorrectly as GDM and reporters state that it would have obviated the need for OGTT in $61.8 \%$ of cases. ${ }^{25}$ In a smaller retrospective study of 145 high-risk Saudi Arabian women, Aldasouqi and colleagues, in 2008, demonstrated the use of HbA1c in detecting $87 \%$ of the patients with GDM diagnosed on OGTT, missing $12 \%$. However, in this study, the cut-off $\mathrm{HbAlc}$ was $6 \%(42 \mathrm{mmol} / \mathrm{mol}) .{ }^{26}$

Other trials determined that the normal mean HbAlc values in Asian Indian women ranged between 5.36 $\pm 0.36 \%$ and $\geq 6 \%(42 \mathrm{mmol} / \mathrm{mol})$ in women with GDM in a study of 507 women. ${ }^{27}$ This study was interesting in that all trimesters were studied. Women who had a positive HbA1c but negative OGTT in the first trimester subsequently developed GDM. ${ }^{27}$ The implication of this is twofold. First, the HbAlc false positives identified in other studies may have actually been true positives with OGTT results being false negatives. Second, if the results of this study are reproducible, then management instituted earlier may have an impact on outcome for babies of mothers who, despite being screened, detected and treated during third trimester, still suffer the consequences of GDM.

Genetically determined variations in the degree of glycosylation of $\mathrm{Hb}$, independent of glycaemia, are thought to exist and are reflected in ethnic differences in HbAlc levels. ${ }^{8}$ This suggests that population reference ranges need to be established prior to universally implementing HbAlc as a screening test in gestational diabetes. It is worth noting that the vast majority of our studied population were Caucasian (94\%).
The use of HbA1c as a screening tool for gestational diabetes has yet to be evaluated in an Australian population. To our knowledge, there are no published data comparing the $75 \mathrm{~g}$ two-step OGTT as per current guidelines with HbAlc in establishing the diagnosis of GDM. It is anticipated that validating the diagnostic utility of HbAlc in pregnancy in Australia would result in a reduction in the burden of testing, increase patient access and compliance, therefore facilitate the management of the gestational diabetic mother and perhaps improve perinatal and maternal outcomes.

We found that the application of HbAlc as a method for screening GDM within the Australian population needs further refining and definition for its use. Outside of pregnancy, it has been established that HbAlc measurement can accelerate and facilitate patient screening, diagnosis and management of diabetes. The usual cut-off value for diagnosing diabetes outside pregnancy seems to be much higher than the cut-off value needed to diagnose diabetes associated with pregnancy. This is in concordance with other studies already detailed.

The results of our study indicate that using an HbAlc level of $5.4 \%(36 \mathrm{mmol} / \mathrm{mol})$ at third trimester (26 weeks) has a specificity of $95 \%$, sensitivity of $27 \%$ and NPV of $91 \%$ in detecting GDM, in line with the reference range for pregnancy reported by other studies. ${ }^{17} 25$ Using a cut-off value of HbA1c $5.1 \%$ $(32 \mathrm{mmol} / \mathrm{mol})$, the sensitivity increased to $55 \%$, at the expense of specificity, which decreased to $80 \%$. The positive association between HbAlc and OGTT is an advantage, but the low sensitivity of HbAlc becomes a hurdle in standardising such a test in pregnancy.

Further investigations are required to integrate $\mathrm{HbAlc}$ as a single, non-fasting diagnostic test for GDM. However, the high NPV may make it useful as an initial screening test. For example, patients with an HbA1c $>5.4 \%(36 \mathrm{mmol} / \mathrm{mol})$ should proceed with an OGTT. This alone would generate a significant reduction in the burden of testing.

It is worth noting that the additional disadvantages of OGTT were potentially avoided by the use of HbAlc. These include the need to fast, non-toleration of glucose ingestion, nausea, a more than $2 \mathrm{~h}$ stay in the laboratory, multiple venipunctures, associated stress and discomfort, greater use of consumables, and finally, increased time requirements on the blood nurse and the associated costs.

Our study has a few shortcomings due to the lack of sensitivity of HbAlc and that some patients, although a small number, will be missed in diagnosis of GDM. Therefore, further optimisation of the test is required prior to its application as a screening tool for GDM. It is likely that the pathophysiology of GDM is different from diabetes mellitus (DM) in the general population. However, GDM may be an indicator of increased risk of non-insulin-dependent type $2 \mathrm{DM}$ in the postnatal period. Pregnancy is a state of insulin resistance. Hormones secreted by the placenta, including growth 
hormone, corticotropin-releasing hormone, placental lactogen and progesterone, all act to increase insulin resistance in the mother, serving to ensure adequate supply of nutrients to the developing fetus. ${ }^{28}$ Where the mother has insufficient pancreatic function to cope with this increasing insulin resistance, diabetes ensues.

In contrast, in type 2 (non-pregnant) DM, increasing insulin resistance obviously is not mediated by a placenta but rather by a complex interplay between genetic predisposition, obesity and decreased physical activity. Abdominal fat is metabolically active, producing hormones that promote insulin resistance. Leptin, tumor necrosis factor- $\alpha$ and resistin are among the many 'adipokines' implicated in insulin resistance and subsequent development of type $2 \mathrm{DM}^{29-31}$ Adipose cells, furthermore, are thought to trigger chronic inflammation, which in turn contributes to the development of insulin resistance. $^{32}$

However, the difference in the performance of HbAlc in non-pregnant versus pregnant populations may not be entirely explained by different pathophysiology.

In summary, employing a cut-off value for HbAlc at $5.4 \%(36 \mathrm{mmol} / \mathrm{mol})$ for detecting GDM showed NPV of $91 \%$ and specificity of $95 \%$. Similar results could be achieved with HbA1c level $>5.1 \%$ as a screening tool for GDM. The high specificity and NPV value may be useful as an initial screening test for GDM. This may result in significant reduction in the burden of testing on both patients and testing facility, staff and resources. Further investigations are required to integrate $\mathrm{HbAlc}$ as a single non-fasting screening tool for GDM with optimisation of the cut-off value.

\section{Author affiliations}

${ }^{1}$ Department of Medicine, Launceston General Hospital, Launceston, Tasmania, Australia

${ }^{2}$ School of Health Sciences, University of Tasmania, Launceston, Tasmania, Australia

${ }^{3}$ Menzies Institute for Medical Research, University of Tasmania, Launceston, Tasmania, Australia

${ }^{4}$ Department of Obstetrics and Gynaecology, Launceston General Hospital and Royal Hobart Hospital, Launceston, Tasmania, Australia

${ }^{5}$ Pathology Department, Launceston General Hospital, Launceston, Tasmania, Australia

${ }^{6}$ Australian National Health and Medical Research Council Clinical Trials Centre, Sydney, New South Wales, Australia

Acknowledgements The authors wish to acknowledge and thank Mr David Seaton, Manager of Pathology Department, Launceston General Hospital, Tasmania, Australia, for his kind help, guidance and technical support throughout the research process as well as all staff of the Pathology Department, Launceston General Hospital, for their enormous help in conducting this study. They also thank sincerely Ms Anne-Sophie Veillard and Valerie Gares from the Australian National Health and Medical Research Council Clinical Trials Centre for their kind help in conduction of the statistical analyses. Finally, they wish to thank sincerely Dr Brooke Kirkby and Mr Gerald Bates, Pathology Department, Launceston General Hospital, Tasmania, Australia, for their kind help in reviewing the manuscript.

Contributors AK is the principal investigator of the study who organised and coordinated all aspects of the research including all steps of the manuscript preparation. He is responsible for the study concept, design, writing, reviewing, editing and approving the manuscript in its final form. EP, AMA-B,
IN and AR recruited the patients and contributed in the study design, analysis and interpretation of data, writing the manuscript and reviewed and approved the manuscript in its final form. WC, CT, TB, VG and AC conducted the testing, supervised the patients at the Pathology Department, Launceston General Hospital, and drafted and finally approved the manuscript.

Funding This study was supported by the Pathology Department, Launceston General Hospital, Launceston, Tasmania, Australia, in affiliation to the University of Tasmania, Australia. Pathology Department provided logistic and monetary support with no influence in the study design; collection, analysis, and interpretation of data; writing the research report; and the decision to submit the manuscript for publication. This is an investigator-initiated study. All aspects of the study conception, design, administration, data collection, analysis and presentation have been undertaken independently of any sponsor.

Competing interests None declared.

Patient consent Obtained.

Ethics approval The trial was approved by Tasmanian Human Ethics Committee, Australia, as a part of another trial targeting the same population.

Provenance and peer review Not commissioned; externally peer reviewed.

Data sharing statement No additional data are available.

Open Access This is an Open Access article distributed in accordance with the Creative Commons Attribution Non Commercial (CC BY-NC 4.0) license, which permits others to distribute, remix, adapt, build upon this work noncommercially, and license their derivative works on different terms, provided the original work is properly cited and the use is non-commercial. See: http:// creativecommons.org/licenses/by-nc/4.0/

\section{REFERENCES}

1. Casey BM, Lucas MJ, Mclntire DD, et al. Pregnancy outcomes in women with gestational diabetes compared with the general obstetric population. Obstet Gynecol 1997;90:869-73.

2. Nankervis A, Mclntyre HD, Moses RG, et al. Testing for gestational diabetes mellitus in Australia. Diabetes Care 2013;36:e64. doi:10.2337/dc12-2345

3. d'Emden M. Glycated haemoglobin for the diagnosis of diabetes. Aust Prescriber 2014;37:98-100.

4. Hoang $\mathrm{H}$, Le Q. Comprehensive picture of rural women's needs in maternity care in Tasmania, Australia. Aust $J$ Rural Health 2013;21:197-202.

5. Colaguiri S, Davies D, Girgis S, et al. National evidence based guideline for case detection and diagnosis of type 2 diabetes. Canberra: Diabetes Australia and National Health and Medical Research Council, 2009.

6. Selvin E, Crainiceanu CM, Brancati FL, et al. Short-term variability in measures of glycemia and implications for the classification of diabetes. Arch Intern Med 2007;167:1545-51.

7. Pandit MK, Burke J, Gustafson AB, et al. Drug-induced disorders of glucose tolerance. Ann Intern Med 1993;118:529-39.

8. Lippi G, Targher G. Glycated hemoglobin (HbA1c): old dogmas, a new perspective? Clin Chem Lab Med 2010;48:609-14.

9. Agarwal MM, Hughes PF, Punnose J, et al. Gestational diabetes screening of a multiethnic, high-risk population using glycated proteins. Diabetes Res Clin Pract 2001;51:67-73.

10. Agarwal MM, Dhatt GS, Punnose J, et al. Gestational diabetes: a reappraisal of HBA1c as a screening test. Acta Obstet Gynecol Scand 2005;84:1159-63.

11. Pollak A, Brehm R, Havelec $L$, et al. Total glycosylated hemoglobin in mothers of large-for-gestational-age infants: a postpartum test for undetected maternal diabetes? Biol Neonate 1981;40:129-35.

12. Griffiths RJ, Vinall PS, Stickland MH, et al. Haemoglobin A1c levels in normal and diabetic pregnancies. Eur J Obstet Gynecol Reprod Biol 1987;24:195-200.

13. Moses RG. HbA1c and the diagnosis of gestational diabetes mellitus-a test whose time has not yet come. Diabetes Res Clin Pract 2012;98:3-4.

14. Metzger BE, Lowe LP, Dyer AR, et al. Hyperglycemia and adverse pregnancy outcomes. N Engl J Med 2008;358:1991-2002.

15. Metzger BE, Gabbe SG, Persson B, et al, International Association of Diabetes and Pregnancy Study Groups Consensus Panel. International association of diabetes and pregnancy study groups 
recommendations on the diagnosis and classification of hyperglycemia in pregnancy. Diabetes Care 2010;33:676-82.

16. Nielsen LR, Ekbom P, Damm P, et al. HbA1c levels are significantly lower in early and late pregnancy. Diabetes Care 2004:27:1200-1.

17. O'Connor C, O'Shea PM, Owens LA, et al Trimester-specific reference intervals for haemoglobin $\mathrm{A} 1 \mathrm{c}(\mathrm{HbA1c})$ in pregnancy. Clin Chem Lab Med 2012;50:905-9.

18. Tian QW, Xuan C, Wang HW, et al. Diagnostic accuracy of glycosylated hemoglobin in Chinese patients with gestational diabetes mellitus: a meta-analysis based on 2,812 patients and 5,918 controls. Genet Test Mol Biomarkers 2013;17:687-95.

19. http://adips.org/downloads/ ADIPSConsensusGuidelinesGDMACCEPTEDFINAL.pdf

20. Khalafallah AA, Dennis A, Bates J, et al. Three-year follow-up of a randomised clinical trial of intravenous versus oral iron for anaemia in pregnancy. BMJ Open 2012;2:pii: e000998.

21. Khalafallah AA, Dennis AE. Iron deficiency anaemia in pregnancy and postpartum: pathophysiology and effect of oral versus intravenous iron therapy. J Pregnancy 2012;2012:630519.

22. Khalafallah AA, Dennis AE, Ogden $\mathrm{K}$, et al. A prospective randomized, controlled trial of intravenous versus oral iron for moderate iron deficiency anaemia of pregnancy. $J$ Intern Med 2010;268:286-95.

23. Hartland AJ, Smith JM, Clark PM, et al. Establishing trimester- and ethnic group-related reference ranges for fructosamine and $\mathrm{HbA1c}$ in non-diabetic pregnant women. Ann Clin Biochem 1999; 36:235-7.

24. Gillery P. A history of $\mathrm{HbA1c}$ through Clinical Chemistry and Laboratory Medicine. Clin Chem Lab Med 2013;51:65-74.

25. Rajput R, Yogesh Y, Rajput M, et al. Utility of HbA1c for diagnosis of gestational diabetes mellitus. Diabetes Res Clin Pract 2012:98:104-7.

26. Aldasouqi SA, Solomon DJ, Bokhari SA, et al. Glycohemoglobin A1c: a promising screening tool in gestational diabetes mellitus. Int J Diabetes Dev Ctries 2008;28:121-4.

27. Balaji V, Madhuri BS, Ashalatha S, et al. A1C in gestational diabetes mellitus in Asian Indian women. Diabetes Care 2007;30:1865-7.

28. Butte NF. Carbohydrate and lipid metabolism in pregnancy: normal compared with gestational diabetes mellitus. Am J Clin Nutr 2000;71 (5 Suppl):1256S-61S.

29. Li S, Shin HJ, Ding EL, et al. Adiponectin levels and risk of type 2 diabetes: a systematic review and meta-analysis. JAMA 2009;302:179-88.

30. Hotamisligil GS, Shargill NS, Spiegelman BM. Adipose expression of tumor necrosis factor-alpha: direct role in obesity-linked insulin resistance. Science 1993;259:87-91.

31. Steppan CM, Bailey ST, Bhat S, et al. The hormone resistin links obesity to diabetes. Nature 2001;409:307-12.

32. Vandanmagsar B, Youm YH, Ravussin A, et al. The NLRP3 inflammasome instigates obesity-induced inflammation and insulin resistance. Nat Med 2011;17:179-88. 